\title{
A fetus excised from the small intestinal mesentery of a neonate (fetus in fetu): a case report
}

\author{
Mohammad Ahmad Alekrashy ${ }^{1}$, Ahmed Refaat Khodary ${ }^{1 *}$ (D), Amr Abd Almohsen Alnemr ${ }^{2}$, \\ Ahmed A. Elsammak ${ }^{3}$ and Sherief M. Elgebaly ${ }^{4}$
}

\begin{abstract}
Background: Fetus in fetu is a rare congenital anomaly. Its incidence is $1 / 500,000$ births. So, pediatric surgeons may encounter this pathology only once or twice during their professional careers.

Case presentation: We present a rare case of a fetus extracted from the small intestinal mesentery of a healthy neonate who was explored after delivery. The extracted fetal mass included a fully differentiated skull and limbs with a celomic cavity. The fetal mass was supplied by a main feeding vessel branching from the superior mesenteric artery.

Conclusion: Fetus in fetu, despite being a rare variant, must be kept in mind when dealing with a neonatal abdominal mass showing bony parts on radiography.
\end{abstract}

Keywords: Case report, Fetus, In fetu, Small intestine

\section{Background}

Fetus in fetu (FIF) is a rare congenital anomaly. Its incidence is $1 / 500,000$ births [1]. So, pediatric surgeons may encounter this pathology only once or twice during their professional careers [2].

FIF was first described by Johann Friedrich in the early nineteenth century [3]. It was later defined by Willis as a mass containing a vertebral axis, often with an appropriate arrangement of limbs or other organs around this axis [3].

Gonzalez-Crussi confirmed this definition, describing FIF as "a highly organo-typic development with vertebral axis and mature circumferential tissue arrangement" [4].

The relationship between teratoma and FIF is vague with no clear difference between them. While teratoma is a true neoplasm composed of multiple tissues foreign to the part in which it arises [5], some writers emphasize

\footnotetext{
*Correspondence: ahmedrefaatkhodary@gmail.com

${ }^{1}$ Pediatric Surgery Department, Faculty of Medicine, Zagazig University,

Zagazig, Egypt
}

Full list of author information is available at the end of the article the presence of the vertebral column as a distinct feature in diagnosing FIF [6]. FIF is characterized by organized vertebral, musculoskeletal, and organ structures that may resemble the fetus [7]. Parasitic twins are joined to an otherwise relatively normal fetus in one of the same sites of union as intact conjoined twins. They usually consist of externally attached supernumerary limbs, not infrequently with some viscera, but very rarely with a functional heart or brain [8].

Many theories were proposed to explain the etiology of $\mathrm{FIF}^{[9]}$. The most prevalent hypothesis is that it is due to an embryological insult in a diamniotic mono-chorionic pregnancy with an unequal division of the totipotent inner cell mass within the developing blastocyst which results in small cell mass within a maturing sister embryo [9].

To qualify as an FIF, one of the following characteristics must be present: a mass enclosed within a distinct sac, partially or completed covered by skin, grossly recognizable anatomic features, and attached to the host by a pedicle containing a few relatively large blood vessels [6]. FIF 
tumors are usually single, rarely multiple, and are genetically identical to their host, as proven by karyotyping and DNA analysis $[10,11]$.

\section{Case presentation}

A 27-years-old female followed up her second pregnancy with her gynecologist who suspected an abnormal mass in the fetal abdomen at the 6th month of pregnancy (Fig. 1), by routine pregnancy ultrasonography. Her first baby is a 2-year-old healthy male with no congenital anomalies.

Four-dimension (4D) ultrasonography (Fig. 2) described a polycystic mass in the left side of the baby's abdomen suspecting complicated meconium ileus. At full term, delivery was done by cesarean section.

Inspection of the abdomen revealed moderate abdominal distention, dilated veins over the anterior

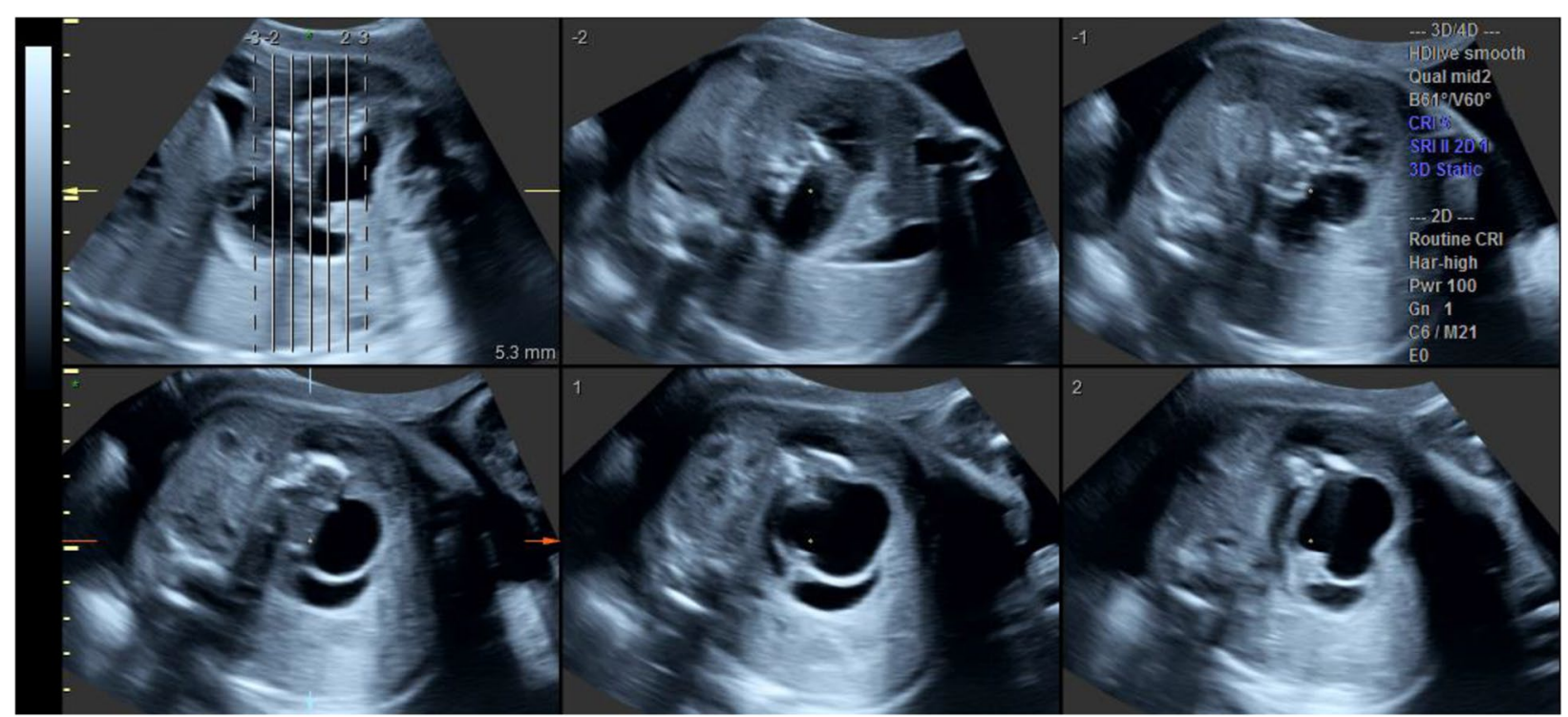

Fig. 1 Prenatal ultrasound showing a polycystic abdominal swelling in the fetus

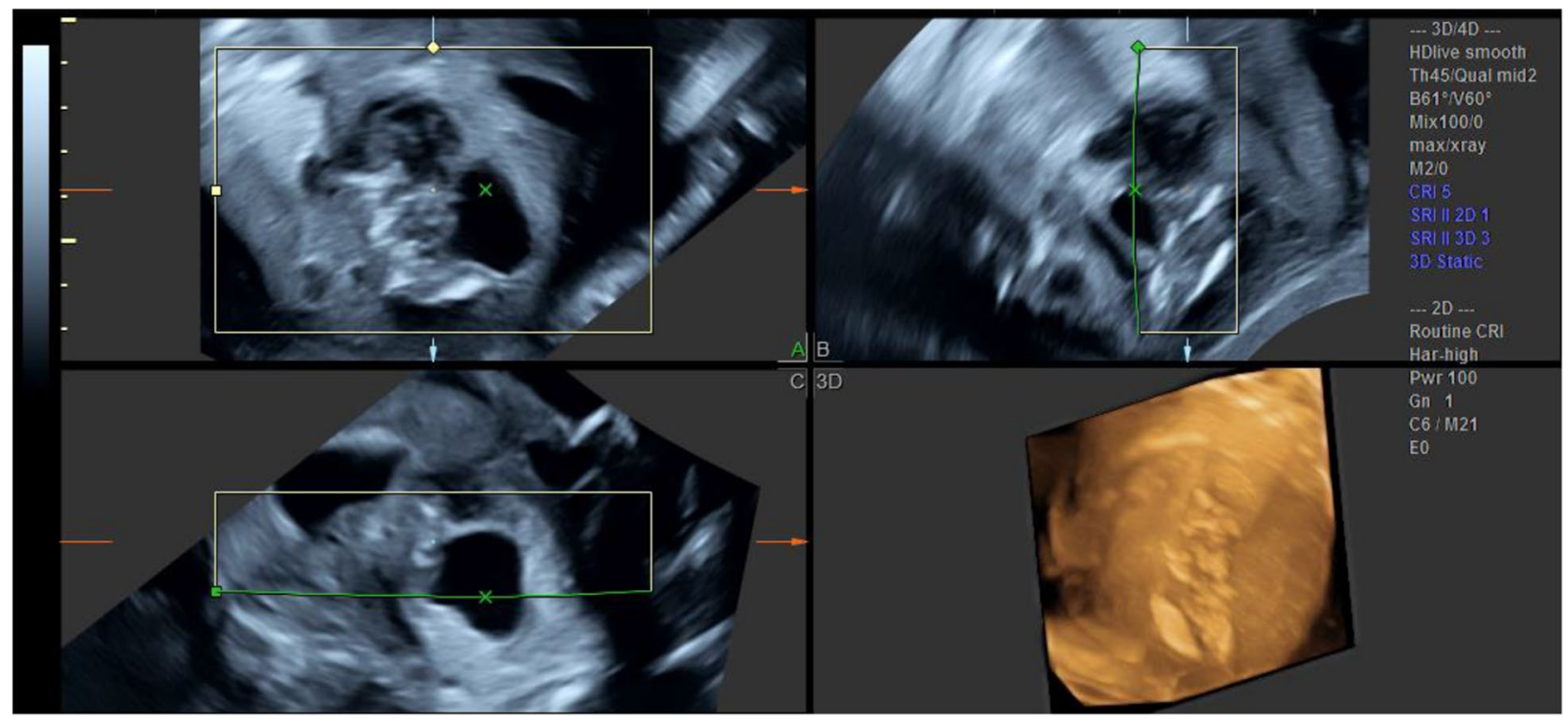

Fig. 2 4D pregnancy ultrasound of the fetus 
abdominal wall, and erythematous patches over the skin of the left lumbar region.

Superficial palpation of the abdomen revealed partially solid-partially cystic mass occupying the whole left side of the abdomen and crossing midline.

The baby was admitted immediately to NICU. Rectal examination revealed regular meconium. Plain erect X-ray was done which revealed no fluid levels nor pneumoperitoneum, so oral feeding was started and bowel movements were normal so meconium ileus was excluded. Echocardiography was done which revealed a small ASD ostium secondum.

Laboratory investigations revealed a total leucocytic count of $9.76 \times 10^{3} / \mu \mathrm{L}$ with $33 \%$ neutrophils.

Multi-slice CT for the abdomen and pelvis (Fig. 3) was done for the baby after $24 \mathrm{~h}$ of delivery which revealed a large retroperitoneal mass measuring $78 \times 67 \times 50 \mathrm{~mm}$ with well-defined margins. It appeared hypodense with multilocular cystic areas, containing calcified structures in a configuration of fetal bones (skull, spines, femur, and pelvic bones). The mass was displacing the bowel loops upwards and laterally (Fig. 3).

\section{Operative details}

At the age of 3 days and after routine laboratory investigations, informed consent was obtained to proceed with surgery. Under general anesthesia, supra-umbilical transverse exploratory incision was done.

Yellowish sero-purulent fluid was found free in the peritoneal cavity. Suction and lavage were done. A mass was found enclosed within the mesentery of the jejunum just near the Dudeno-Jejunal junction with a skull covered by fetal hair looking through the transparent mesentery (Fig. 4).

The inferior layer of the mesentery was incised and bluntly dissected over the sac covering the mass. An

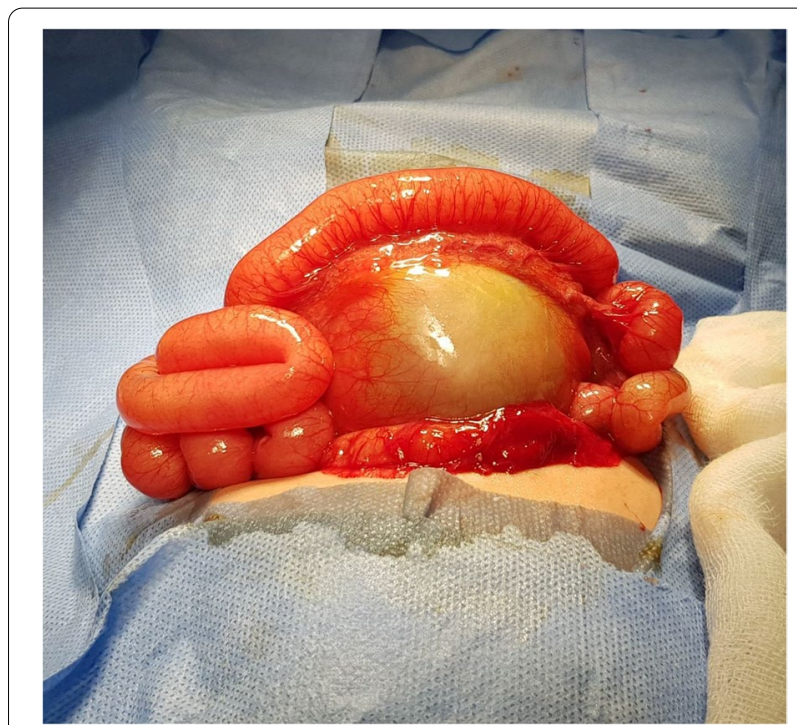

Fig. 4 The skull of the fetus bulging through the small intestinal mesentery of the delivered baby

artery was found branching from the superior mesenteric artery and passing through the sac till the umbilical area of the baby looking like an umbilical artery feeding the mass (Fig. 5). This artery was ligated and divided. Other smaller discrete vessels coming from superior mesenteric vessels to different areas of the mass were ligated and divided as well.

The mass was extracted (Fig. 6) and the abdomen was explored thoroughly to exclude other anomalies. The peritoneal cavity was then irrigated and mass closure was performed. No drains were inserted.

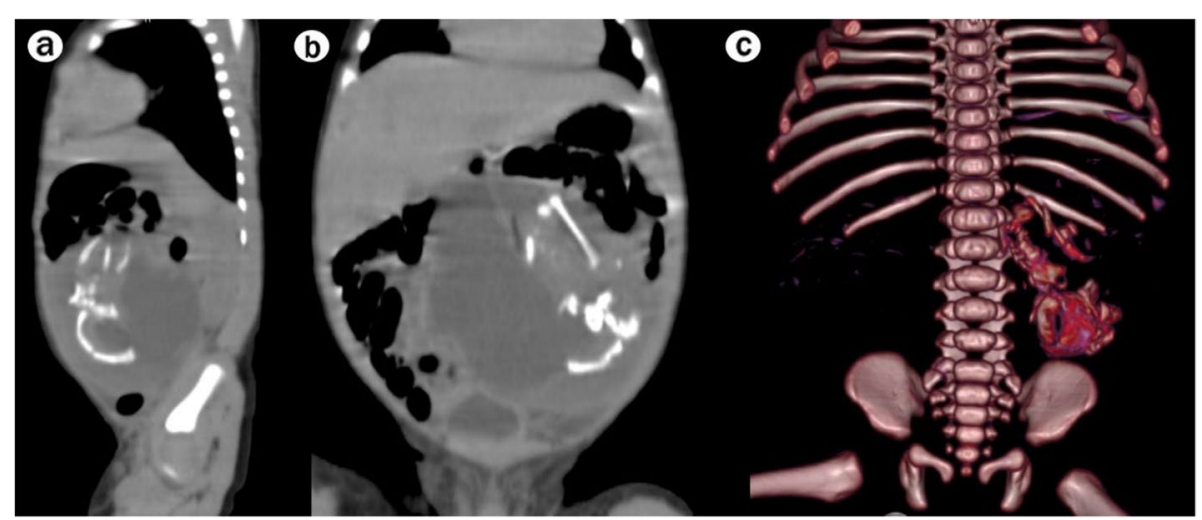

Fig. 3 Multislice CT of the abdomen and pelvis of the newborn baby after delivery. $\mathbf{a}$, b Showing the ossified bony parts within the fetal abdomen. c $\mathrm{A} 3 \mathrm{D}$ reconstruction image of the suspected mass 


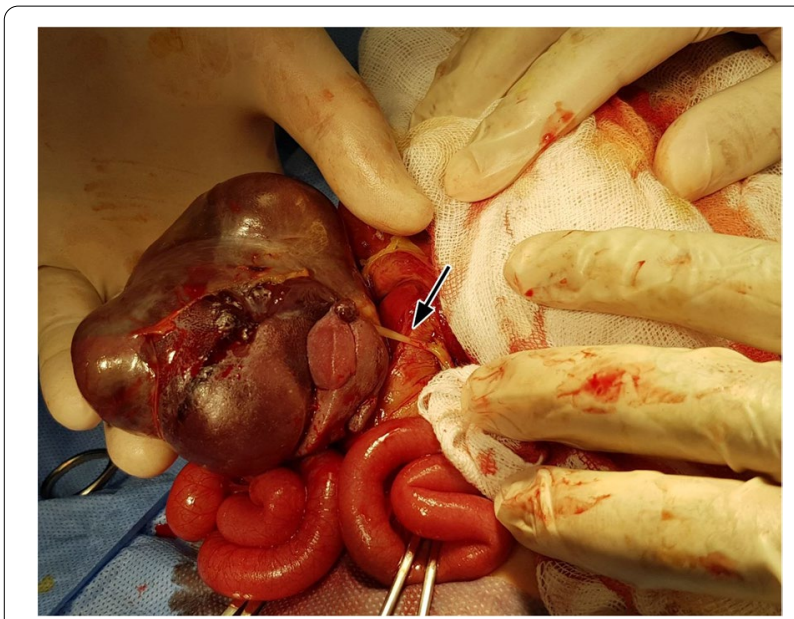

Fig. 5 The extracted fetal mass based on a main feeding vessel (black arrow)

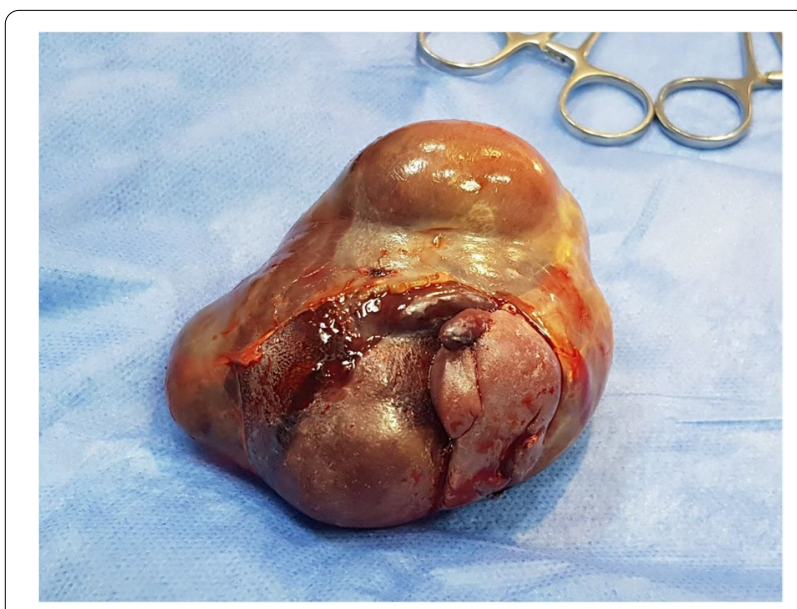

Fig. 6 Extracted fetal mass

\section{Post-operative course}

Post-operatively the infant was transferred back to NICU. Bowel movement was regained within $24 \mathrm{~h}$ and feeding was started gradually by suckling and full feeding was reached within $48 \mathrm{~h}$ post-operatively. The baby was discharged home on the fourth post-operative day with a total hospitalization of 1 week and followed up in OPD for wound dressing and for 6 months later and has been doing well during his follow-up with no complications.

\section{Details about the extracted fetal mass}

Opening the membranes over the mass revealed what looked like a fetus folded ventrally over the caelomic cavity with ventral hernia revealing incomplete parts of the gut. The fetus showed flexed upper and lower limbs over the abdomen. A male genital bud was found in its normal location (Fig. 7).

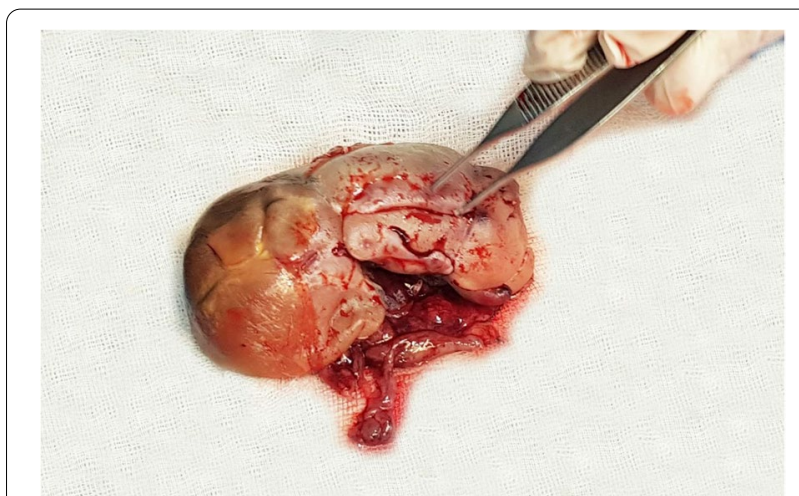

Fig. 7 The extracted fetal mass after opening of the membranes showing a head and flexed upper and lower limbs

The fetal mass was sent for histopathological examination. Histopathological examination of sections from different parts of the fetus revealed the presence of vertebral bone trabeculae with bone marrow spaces, cartilaginous foci, covering skin with adnexa, islands of mucosa together with fetal membranes, and chorionic villi. No evidence of immature tissues or neoplastic transformation was seen in the examined sections.

\section{Discussion}

Our fetal mass was found retroperitoneal in the mesentery of the small intestine. In $70 \%$ of the reported cases, the main presenting complaint was an abdominal mass, of which $80 \%$ were predominantly retroperitoneal [9].

However, it may also be found in more uncommon sites, such as the oral cavity, sacrococcygeal region, and scrotum [12-14]. Other even rarer localizations, such as intracranial FIF, have also been reported [5, 8].

Our case was diagnosed as an abdominal mass intrauterine in late pregnancy the highly suspicion of being FIF by CT was just after birth. In most cases, and in concurrence with published reports, FIF presented during infancy by symptoms suggestive of abdominal distension, as well as feeding or respiratory difficulties. Only a few reported cases were above the age of 2 years [2].

CT scan was the most commonly used diagnostic modality in a study in 2019 by Taher et al. [2], with a preoperatively confirmed diagnosis in four cases and findings strongly suggestive of FIF, such as long bone structures and vertebrae, in four patients (sensitivity $80 \%)$. The latter are the typical findings that differentiate FIF from other causes of intra-abdominal calcification, including teratoma, meconium pseudocyst, neuroblastoma, adrenal hemorrhage, and viral infection [2].

Although most cases of FIF can be resected easily, the vascular supply can be variable and therefore presents a 
potential pitfall during the operation. Others agree that resection of FIF requires great care during dissection of the vessels to avoid unintended injury [15]. Resection of our FIF was easy after opening the peritoneum over the mass then blunt dissection of the whole mass out of the retroperoperitoneum.

While most isolated cases of FIF with aortic blood supply are easily removed, adherence to surrounding structures can complicate the procedure immensely [2].

Potential for malignant transformation is rare in FIF since only one case has been reported in literature [16]. In an earlier study, only a patient who succumbed after the biliary leak was found to have immature elements in the histopathologic analysis [16]. Complete excision of FIF is therefore curative in most cases, regular scheduled follow-up by tumor markers (such as AFP, $\beta$-hCG, and carcinoembryonic antigen) and abdominal ultrasound seem necessary only in cases with immature tissue components [2].

\section{Conclusion}

Fetus in fetu, despite being a rare variant, must be kept in mind when dealing with a neonatal abdominal mass showing bony parts on radiography.

\section{Abbreviations \\ 4D: Four dimensions; AFP: Alpha-fetoprotein; ASD: Atrial septal defect; CT: Computed tomography; DNA: Deoxyribonucleic acid; FIF: Fetus in fetu; hCG: Human chorionic gonadotrophins; NICU: Neonatal intensive care unit; OPD: Outpatient Department.}

\section{Acknowledgements}

Not applicable.

\section{Authors' contributions}

All authors read and approved the final manuscript. MAA made substantial contributions in the operative procedure as well as drafting the manuscript. ARK revised and participated in writing the manuscript and language revision. AAA first diagnosed the case and participated with a prenatal ultrasound scan. AAE contributed to the diagnostic workup and investigations. SME supervised the medical condition and participated in writing.

\section{Funding}

This research did not receive any specific grant from funding agencies in the public, commercial, or not-for-profit sectors. No competing financial interests exist.

\section{Availability of data and materials}

The datasets used and/or analyzed during the current study are available from the corresponding author on reasonable request.

\section{Declarations}

\section{Ethics approval and consent to participate}

The study was approved by the Institutional Review Board (IRB) at our institution and informed consent was obtained from the patient.

\section{Consent for publication}

Written informed consent was obtained from the patient for publications.

\section{Competing interests}

The authors declare that they have no competing interests.

\section{Author details}

${ }^{1}$ Pediatric Surgery Department, Faculty of Medicine, Zagazig University, Zagazig, Egypt. ${ }^{2}$ Obstetrics and Gynecology Department, Faculty of Medicine, Zagazig University, Zagazig, Egypt. ${ }^{3}$ Radiology Department, Faculty of Medicine, Zagazig University, Zagazig, Egypt. ${ }^{4}$ Pediatric Department, Faculty of Medicine, Zagazig University, Zagazig, Egypt.

Received: 1 April 2021 Accepted: 6 October 2021

Published online: 03 January 2022

\section{References}

1. Matsubara N, Akasaka Y, Kanagaki M, Okamoto S. A case report of fetus in fetu with an aorta-like structure visualized by contrast-enhanced CT. Radiol Case Rep. 2020 Oct 13;15(12):2645-8. https://doi.org/10.1016/j. radcr.2020.10.006

2. Taher HMA, Abdellatif M, Wishahy AMK, Waheeb S, Saadeldin Y, Kaddah S, et al. Fetus in fetu: lessons learned from a large multicenter cohort study. Eur J Pediatr Surg. 2020 Aug;30(4):343-9. https://doi.org/10.1055/s-00391698765

3. Parashari UC, Luthra G, Khanduri S, Khanduri S, Bhadury S, Upadhyay D. Diagnostic dilemma in a neglected case of fetus-in-fetu solved with magnetic resonance imaging and MDCT-a case report and review of literature. J Radiol Case Rep. 2011;5(10):29-37. https://doi.org/10.3941/ jrcr.v5i10.833.

4. Gonzalez-Crussi F. Extragonadal Teratomas (atlas of tumor pathology). 2nd ed. Washington, DC: Armed Forces Institute of Pathology; 1982. p. 20-4.

5. Willis RA. The borderland of embryology and pathology. 2nd ed. Washington, DC: Butterworths; 1962. p. 442-62.

6. Brand A, Alves MC, Saraiva C, et al. Fetus in fetu-diagnostic criteria and differential diagnosis-a case report and literature review. J Pediatr Surg. 2004:39:616-8. https://doi.org/10.1016/j.jpedsurg.2003.12.029.

7. Richard G. Azizkhan. Teratomas and other germ cell tumors. In: Pediatric Surgery, $6^{\text {th }}$ ed. Elsavier 2006; $P 558$.

8. Spencer R. Parasitic conjoined twins: external, internal (fetuses in fetu and teratomas), and detached (acardiacs). Clin Anat. 2001;14(06):428-44.

9. Pang KK, Chao NS, Tsang TK, Lau BY, Leung KY, Ting SH, Leung MW, Liu KK. From observation to aetiology: a case report of a twin fetus-in-fetu and a revisit of the known rarity. Hong Kong Med J. 2015 Feb;21 (1):80-3. doi: https://doi.org/10.12809/hkmj133925. PMID: 25686708.

10. Ji $Y$, Chen $S$, Zhong $L$, Jiang $X$, Jin $S$, Kong $F$, et al. Fetus in fetu: two case reports and literature review. BMC Pediatr. 2014 Apr 2;14:88. https://doi. org/10.1186/1471-2431-14-88.

11. Gerber RE, Kamaya A, Miller SS, Madan A, Cronin DM, Dwyer B, et al. Fetus in fetu: 11 fetoid forms in a single fetus: review of the literature and imaging. J Ultrasound Med. 2008 Sep;27(9):1381-7. https://doi.org/10.7863/ jum.2008.27.9.1381.

12. Abdulraheem NT, Nasir AA, Abdur-Rahman LO, Akanbi OR, Olanrewaju MO, Alada MA, et al. Oral fetus-in-fetu: a case report. J Ped Surg Case Reports. 2015;3:171-3.

13. Trairongchitmoh c. Sacrococcygeal fetus-in-fetu. J Pediatr Surg Case Rep 2020; 59: 101501. Doi: https://doi.org/10.1016/j.epsc.2020.101501.

14. Ji Y, Song B, Chen $\mathrm{S}$, et al. Fetus in fetu in the scrotal sac: case report and literature review. Medicine (Baltimore). 2015;94(32):e1322. https://doi.org/ 10.1097/MD.0000000000001322.

15. Khalifa NM, Maximous DW, Abd-Elsayed AA. Fetus in fetu: a case report. J Med Case Rep. 2008;2:2

16. Keshava Murthy M, Hanumanthaiah, Adarsh E et al. Fetus in fetu: a case report and review of literature. JIMSA 2014;27(01):26.

\section{Publisher's Note}

Springer Nature remains neutral with regard to jurisdictional claims in published maps and institutional affiliations. 